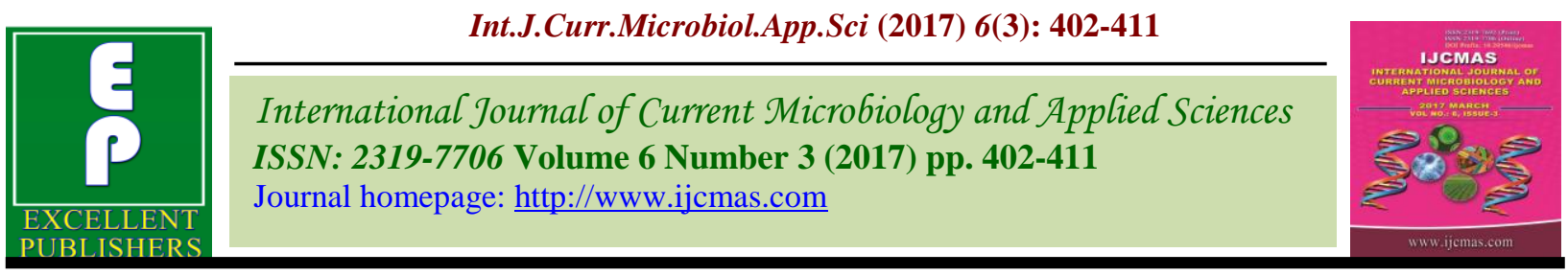

Original Research Article

https://doi.org/10.20546/ijcmas.2017.603.046

\title{
Detoxification of Heavy Metals Using Microbial Biosurfactant
}

\author{
M. Meenakshisundaram* and M. Pramila \\ ${ }^{1} \mathrm{PG}$ and Research Department of Biotechnology, Nehru Memorial College, (Autonomous), \\ Puthanampatti, Tiruchirappalli District, Tamil Nadu, India \\ ${ }^{2}$ Department of Botany, Nehru Memorial College, (Autonomous), Puthanampatti, Tiruchirappalli \\ District, Tamil Nadu, India \\ *Corresponding author
}

\section{A B S T R A C T}

\begin{tabular}{|l|}
\hline Ke y w o r d s \\
Biosurfactants, \\
Heavy metals, \\
$\begin{array}{l}\text { Detoxification, } \\
\text { Pseudomonas } \\
\text { putida. }\end{array}$ \\
\hline Article Info \\
\hline $\begin{array}{l}\text { Accepted: } \\
\text { 10 February } 2017 \\
\text { Available Online: } \\
\text { 10 March } 2017\end{array}$ \\
\hline
\end{tabular}

In recent times river pollution is a serious and growing problem in most developing countries. Industrial effluents and sewage entering the water bodies are one of the major sources of environmental toxicity, which endangers aquatic biota and deteriorates water quality. Biological methods for the removal of heavy metals from industrial waste may provide an attractive alternative to the physiochemical process. Biosurfactants are one of the compounds that help in alleviating the heavy metals. A large number of bacteria such as Psudomonas sp, Bacillus sp, Acinetobacter sp, Arthrobacter sp are reported to produce biosurfactants. Compared to synthetic compounds, biosurfactants provide the advantages of little or no environmental impact and the possibility of in-situ production. Studies in recent past have exhibited the successful use of biosurfactants for facilitating the degradation of organic pollutants in soil and water. In the light of the above, the present study is aimed to carry out the assessment efficiency of biosurfactants producing bacteria isolated from heavy metal contaminated sites of the uyyokondan river, Tiruchirappalli District, Tamilnadu. Among 9 different strains, were isolated and identified by morphologically and 16S rRNA Sequencing as a Achromobacter denitrificans, Bacillus flexus, Achromobacter xylosoxidans, Bacillus cereus, Pseudomonas medocina, Pseudomonas putida, Bacillus badius, Lysinibacillus xylanilyticus, and Exiguobacterium homiense (99\% homology). The Haemolytic activity, emulsification activity, drop collapsing test as well as oil displacement test were used to determine biosurfactant producing activity of isolated bacterial strains. The bacterial isolates Pseudomonas putida were found to remove heavy metals from the medium.

\section{Introduction}

Surfactants are amphoteric molecules which help in alleviating the non- degradable pollutants that are the major cause of pollution of reverine ecosystem for the past few decades. Biosurfactants refers to any compound from microorganisms that have influence on interfaces like surface acting agents which bring down the interfacial tension between the two liquids. Biosurfactants are produced by plants, animals, and many different microorganisms (Zajic and Panchel, 1976). There are several apparent advantages to the use of biosurfacatnts rather than synthetic ones, as for example biosurfactants are biodegradable, cost-effective, lower toxicity, selectivity, specific activity at 
extreme temperature, $\mathrm{pH}$, and salinity, the possibility of their production through fermentation, their potential applications in environmental protection and management, crude oil recovery, as antimicrobial agents in healthcare and food processing industries. Some species of Pseudomonas are able to produce and excrete a heterogenous structure known as rhamnolipids. Rhamnolipids give good physiochemical properties in term of surface activities, emulsification activities and stabilities. Moreover, these surface active compounds show antimicrobial activities against both pathogenic bacteria and fungi. Due to an increase in concerns regarding environmental protection and also the distinctive properties of the rhamnolipids, it seems that rhamnolipids fulfil the criteria for several industrial and environmental applications like environmental remediation and biological control. Biosurfactants like rhamnolipids have already been commercially manufactured, producing them more economically competitive with other synthetic surfactants. So in the near future, rhamnolipids may be commercially successful biosurfactants. Biosurfactants accelerate the solubilization of hydrophobic chemicals by forming micelles which contain hydrophobic domains where the chemicals are incorporated. Biosurfactants are produced by many different bacterial genera. Though chemical structures of biosurfactants vary widely, but more biosurfactants are anionic or non-ionic. The yield and composition of biosurfactant are affected by growth conditions include carbon sources, culture medium nutrients, temperature, $\mathrm{pH}$, and agitation (Syldatk and Wagner, 1987). Moreover, there are species level difference in the chemical structure of biosurfactants. For example, the rhamnolipids produced by different Pseudomonas species vary both in the number of rhamnose molecules and the length of lipid moiety (Chandrasekaran and Bemiller, 1980). Although it is well known that bacterial cells can complex metals from solution, there is little information in the literature concerning the use of biosurfactants to complex metals. With this perspective in mind, the present work is undertaken to isolate bacteria from a metal contaminated site of the Uyyokondan river, to determine the ability to produce biosurfactant and to assess the efficacy of biosurfactant producing bacteria to remove heavy metal contaminated site of the uyyokondan river.

\section{Materials and Methods}

\section{Sampling}

The study was carried out in Uyyokondan river water resources, Tiruchirappalli District, Tamilnadu. The water samples in uyyokondan river collected and all samples were placed an ice thermoinsulated container (temp inside was not higher than $70^{\circ} \mathrm{C}$ ), and brought to a laboratory where they were immediately analysed.

\section{Isolation and characterization of bacteria}

Bacteria were isolated by serial dilution method and spread plate technique (Sinha, 2006). The isolated bacterial strain were subjected to staining and various morphological, physiological and biochemical characterization such as shape, Gram staining, Indole production, methyl red test, Voges Proskauer test, citrate utilization test, Catalase test, Oxidase test, Urease test, Starch hydrolysis, Nitrate reduction, casein hydrolysis, Coagulase, Gelatinase test (Bensen, 2004).

\section{Identification of strains: 16s Rrna Sequence analysis}

Genomic DNA was extracted from $1 \mathrm{ml}$ of bacterial culture, the culture was pelleted by centrifuging at $12,000 \mathrm{rpm}$ for $2 \mathrm{~min}$. The 
pellet was treated with lysis solution and proteinase $\mathrm{k}$ and incubated at $60^{\circ} \mathrm{C}$ for $30 \mathrm{~min}$. Nucleic acids were precipitated with isopropanol and followed by the ethanol treatment at $10,000 \mathrm{rpm}$ for $10 \mathrm{mins}$. The pellet was washed with $1 \mathrm{ml}$ of $70 \%(\mathrm{v} / \mathrm{v})$ ethanol solution and dissolved in $0.1 \mathrm{ml}$ of a TE buffer. The purity and quantity of DNA was examined by UV absorption spectrum and agarose gel electrophoresis. 16SrRNA PCR Amplification was performed with the help of the following primer sets: $16 \mathrm{~s}-8 \mathrm{~F}\left(5^{\prime}\right.$ -GAGAGTTTGATCCTGGCTCAG-3') and 16s-1495R (5'- CGGCTACCTTGTTACTTC$\left.3^{\prime}\right)$. The following PCR conditions were followed $\left(35\right.$ cycles of $3 \mathrm{~min}$ at $94^{\circ} \mathrm{C}, 1 \mathrm{~min}$ at $500 \mathrm{C}, 2 \mathrm{~min}$ at $72^{\circ} \mathrm{C}$ ) and performed in a thermal cycler (Gradient Mastercycler, Eppenorff, USA). The amplified products were subsequently subjected to gel electrophoresis (Banglore Genei, India), stained with ethidium bromide and documented by gel documentation system.

The amplified 16S rDNA was subjected to agar gel electrophoresis and purified by Qiaquick gel extraction kit (Qiagen, USA). The purified PCR product was sequenced by dideoxy chain termination method using ABI Prism Big Dye Terminator Cycle Sequencing Ready reaction kit as directed in the manufacturer protocol. Sequence reactions were electrophoresed and analysed by ABI Prism 3100 genetic analyser (Applied Biosystems, USA).

The sequences were analysed using the CHECK CHIMERA and the SIMILARITY RANK programs of the Ribosomal Database project (Altrschul et al., 1990). The BLAST analysis was carried out (National Centre for Biotechnology information) to determine the closest bacterial sequences, the closest bacterial sequences were aligned using the Clustal W program (Shingler et al., 1992). Phylogenetic tree was constructed using Clustal $\mathrm{W}$ by distance matrix analysis and the neighbor -joining method (Saitou et al., 1987) (Fig. 1). The confirmed sequences were deposited in Genebank for public access. (Accession numbers KJ452459, KJ452460, KJ452461，KJ452462,KJ452463，KJ452464, KJ452465, KJ452466, and KJ452467).

\section{Screening for biosurfactant production}

\section{Oil spreading technique}

The isolated strains were tested for biosurfactant production through following methods: 10 ul supernatant (from culture broth) was added to the surface of oil as described by Nasr (2009). Occurrence of clear zone was an indication of biosurfactant production. 10ul of culture media without any growth was taken as control.

\section{Haemolytic activity}

Haemolytic assay was performed in blood agar plates (Mulligan et al., 1984). 50 ul broth cultures were spot-inoculated onto blood agar plates and incubated for $48 \mathrm{~h}$ at blood agar plates and incubated for $48 \mathrm{~h}$ at $370 \mathrm{c}$. The plates were visually inspected for zone of clearance (hemolysis) around the colony.

\section{Emulsification measurement}

Emulsification activity was measured according to the method of Cooper and Goldenberg, (1987). $4 \mathrm{ml}$ of culture supernatant, $4 \mathrm{ml}$ of hexadecane were added and vortexed at high speed for $2 \mathrm{~min}$. The mixture was allowed to stand for $10 \mathrm{~min}$ prior to measurement. The emulsification activity is defined as the height of the emulsion layer divided by the total height and expressed as percentage.

\section{Drop collapsing test}

Two microlitre of mineral oil was added to each well of a microtiter plate lid. The lid was 
equilibrated for $1 \mathrm{hr}$ at room temperature and then 5 ul of the culture supernatant was added to the surface of oil. The shape of the oil surface was inspected after $1 \mathrm{~min}$. Biosurfactant producing cultures giving flat drops were scored as Positive +. Those cultures that have rounded drops were scored as negative' - 'indicative of the lack of biosurfactant production (Yuossef et al., 2004).

\section{Production of biosurfactant}

The isolated organism was used for the production of biosurfactant by growing the organism in a specific medium. The choice of carbon source used for production plays an important role on the yield and structure of microbial surfactants. There are microorganisms which produce biosurfactants only when grown on hydrocarbons and others which require simple, water soluble substrates such as carbohydrates and aminoacids.

\section{Production of rhamnolipid from bacterial isolates}

In the present study, biosurfactant production was carried out in water insoluble medium containing $1.5 \%(\mathrm{~V} / \mathrm{V})$ cooked vegetable as substrate along with other chemicals. The cultures were taken in $500 \mathrm{ml}$ Erlenmeyer flasks with $100 \mathrm{ml}$ of medium. Filter sterilized trace element solution was added to medium. Then whole medium is autoclaved and allowed to cool. Then $2 \mathrm{ml}$ of the culture was added to the medium and incubated at 30 0c for 48-72 h.

\section{Extraction of biosurfactant}

During growth, the surfactants was produced and released in to the medium. This surfactant was extracted by the acid precipitation method. At first, the medium was centrifuged at $5000 \mathrm{rpm}$ for 15 minutes. The cell free broth containing surfactant was collected in a separate tube. Then the surfactant in the broth was precipitated at $\mathrm{pH} 2.0$ by adding conc.HCL. The broth was centrifuged again at $5000 \mathrm{rpm}$ for 15 minutes. Now the surfactant was extracted with dichloromethane. Moreover, purification was achieved by recyrstallization. The dichloromethane extract was dissolved in distilled water containing sufficient $\mathrm{NaOH}$ to give $\mathrm{pH}$ 7.0. This solution was filtered with through Whatman No.4 filter paper and reduced to $\mathrm{pH} 2.0$ with Conc.HCL. After centrifugation, the white solid was collected as a pellet.

\section{Effect of biosurfactant on heavy metal removal}

The extracted biosurfactant was used for the removal of metals such as zinc and iron. The nutrient broth medium containing the salts of zinc sulphate and ferrous sulphate was prepared and sterilized. The salts of zinc and iron were added to the medium at a concentration of $10 \mathrm{mg}, 20 \mathrm{mg}, 30 \mathrm{mg}, 40 \mathrm{mg}$, and $50 \mathrm{mg} /$ /itre respectively. The $\mathrm{pH}$ of the medium was adjusted to $7.0-7.2$ and sterilized in an autoclave for 15 minutes. Then the extracted biosurfactant (about $50 \mathrm{ul} / \mathrm{ml}$ ) was inoculated into the medium and incubated at $30^{\circ} \mathrm{c}$ for 24 hours. The medium was kept as Treatment 1 (TI) and the medium with Rhamnolipid was kept as Treatment 2 (T2). The medium without surfactant and organism served as control. The treatment methods were same for both the metals used. Then the tubes were analyzed for the concentration of the metals present after treatment in an Atomic absorbtion spectrophotometer. The sample was analyzed in the Government Soil Testing Laboratory, Tiruchirappalli and the results were noted.

\section{Results and Discussion}

Table 1 indicated the biochemical characterization of bacterial strains isolated from heavy metal contaminated site of the 
river sediment. Standard biochemical characterization indicated that all the isolates are identified as Achromobacter denitrificans, Bacillus flexus, Achromobacter xylosoxidans,
Bacillus cereus, Pseudomonas medocina, Pseudomonas putida, Bacillus badius, Lysinibacillus xylanilyticus, and Exiguobacterium homiense.

Table.1 Morphological and biochemical characteristics of bacteria isolated from Uyyokondan river

\begin{tabular}{|l|c|c|c|c|c|c|c|c|c|}
\hline Characters & Org 1 & Org 2 & Org 3 & Org 4 & Org 5 & Org 6 & Org 7 & Org 8 & Org 9 \\
\hline Gram staining & - & + & - & - & - & - & - & - & - \\
\hline Shape & cocci & cocci & rod & Rod & rod & cocci & rod & cocci & rod \\
\hline $\begin{array}{l}\text { Indole } \\
\text { production }\end{array}$ & - & - & - & - & - & - & - & - & - \\
\hline Methyl red test & - & - & - & - & - & - & - & - & - \\
\hline $\begin{array}{l}\text { Voges-proskauer } \\
\text { test }\end{array}$ & - & - & + & - & - & - & - & + & - \\
\hline $\begin{array}{l}\text { Citrate } \\
\text { Utilization }\end{array}$ & - & - & + & + & - & - & + & + & + \\
\hline Catalase test & - & - & - & - & - & - & - & - & - \\
\hline Oxidase test & - & + & - & - & + & + & - & - & - \\
\hline Urease test & + & + & - & - & + & + & - & + & - \\
\hline $\begin{array}{l}\text { Starch } \\
\text { hydrolysis test }\end{array}$ & - & - & + & + & - & - & - & - & - \\
\hline $\begin{array}{l}\text { Nitrate } \\
\text { reductase test }\end{array}$ & + & + & + & + & + & + & + & + & + \\
\hline $\begin{array}{l}\text { Caesin } \\
\text { hydrolysis test }\end{array}$ & - & + & - & - & - & + & - & - & + \\
\hline Coagulase test & + & - & + & + & - & - & + & - & + \\
\hline Gelatinase test & + & + & + & - & + & + & - & + & - \\
\hline
\end{tabular}

Org - organism; + Positive: - Negative

Table.2 Identification of bacteria by 16s RDNA sequencing

\begin{tabular}{|l|l|l|}
\hline Organisms & Sample source & Identified by 16s RDNA Sequencing \\
\hline 1 & Water & Achromobacter denitrificans \\
\hline 2 & & Bacillus flexus \\
\hline 3 & Water & Achromobacter xylooxidans \\
\hline 4 & Water & Bacillus cereus \\
\hline 5 & Water & Pseudomonas medocina \\
\hline 6 & Water & Pseudomonas putida \\
\hline 7 & Water & Bacillus badius \\
\hline 8 & Water & Lysinibacillus $x y l a n i l y t i c u s$ \\
\hline 9 & Water & Exiguobacterium homiense \\
\hline
\end{tabular}


Table.3 Screening for the production of biosurfactant

\begin{tabular}{|c|c|c|c|c|c|}
\hline Organisms & $\begin{array}{c}\text { Haemolytic } \\
\text { assay }\end{array}$ & $\begin{array}{c}\text { Methylene } \\
\text { blue agar } \\
\text { plate }\end{array}$ & $\begin{array}{c}\text { Drop } \\
\text { collapsing } \\
\text { test }\end{array}$ & $\begin{array}{c}\text { Emulsification } \\
\text { index }\end{array}$ & $\begin{array}{c}\text { Rhamnolipid } \\
\text { (mg/ml) }\end{array}$ \\
\hline 1 & + & + & + & 65.2 & 0.82 \\
\hline 2 & + & + & + & 56.2 & 0.68 \\
\hline 3 & + & + & + & 50.1 & 0.56 \\
\hline 4 & + & + & + & 54.8 & 0.64 \\
\hline 5 & + & + & + & 49.2 & 0.44 \\
\hline 6 & + & + & + & 71.0 & 0.89 \\
\hline 7 & + & + & + & 42.1 & 0.34 \\
\hline 8 & + & + & + & 45.2 & 0.38 \\
\hline 9 & + & + & + & 47.1 & 0.59 \\
\hline
\end{tabular}

Table.4 Effect of biosurfactant on zinc

\begin{tabular}{|c|c|c|c|c|c|c|c|c|c|}
\hline \multirow{2}{*}{$\begin{array}{c}\text { Control } \\
\text { without } \\
\text { Biosurfactant }\end{array}$} & \multicolumn{9}{|c|}{ Concentration of Zinc (mg/l) } \\
\cline { 2 - 11 } & Org 1 & Org 2 & Org 3 & Org 4 & Org 5 & Org 6 & Org 7 & Org 8 & Org 9 \\
\hline 10 & 20.1 & 20.7 & 19.6 & 20.6 & 21.2 & 32.0 & 24.2 & 27,9 & 28.2 \\
\hline 20 & 34.2 & 32.1 & 20.9 & 32.1 & 29.2 & 45.0 & 33.2 & 30.3 & 34.5 \\
\hline 30 & 35.1 & 34.2 & 32.5 & 34.2 & 33.2 & 53.0 & 37.1 & 34.1 & 39.2 \\
\hline 40 & 43.5 & 42.1 & 34.2 & 36.2 & 39.2 & 57.2 & 42.2 & 35.2 & 40.1 \\
\hline 50 & 46.2 & 45.2 & 38.2 & 39.6 & 40.2 & 73.20 & 45.1 & 39.1 & 42.2 \\
\hline
\end{tabular}

Table.5 Effect of biosurfactant on iron

\begin{tabular}{|c|c|c|c|c|c|c|c|c|c|}
\hline \multirow{2}{*}{$\begin{array}{c}\text { Control } \\
\text { without } \\
\text { Biosurfactant }\end{array}$} & \multicolumn{9}{|c|}{ Concentration of Zinc (mg/l) } \\
\cline { 2 - 11 } & Org 1 & Org 2 & Org 3 & Org 4 & Org 5 & Org 6 & Org 7 & Org 8 & Org 9 \\
\hline 10 & 20.6 & 20.9 & 19.9 & 20.9 & 21.4 & 39.0 & 24.8 & 37.9 & 38.2 \\
\hline 20 & 34.9 & 32.9 & 21.9 & 32.9 & 29.7 & 48.0 & 34.2 & 31.3 & 34.5 \\
\hline 30 & 36.1 & 34.3 & 31.5 & 44.2 & 33.6 & 53.0 & 38.1 & 37.1 & 39.2 \\
\hline 40 & 44.5 & 42.7 & 35.2 & 46.2 & 39.8 & 59.2 & 43.2 & 39.2 & 40.8 \\
\hline 50 & 46.2 & 46.2 & 39.2 & 49.6 & 41.2 & 83.20 & 55.1 & 49.1 & 52.2 \\
\hline
\end{tabular}


Plate.1 Zone of clearance due to biosurfactants haemolytic activity

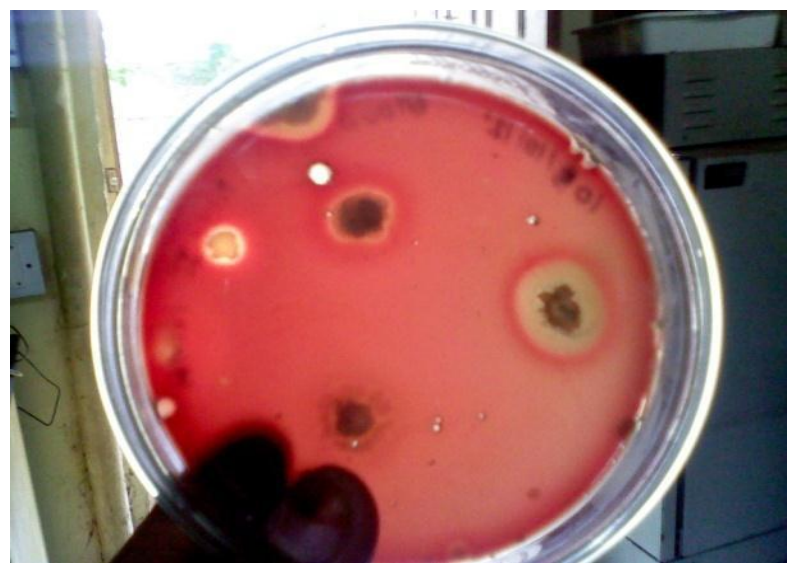

Plate.2 Zone formation by biosurfactant producing bacteria in oil spreading technique

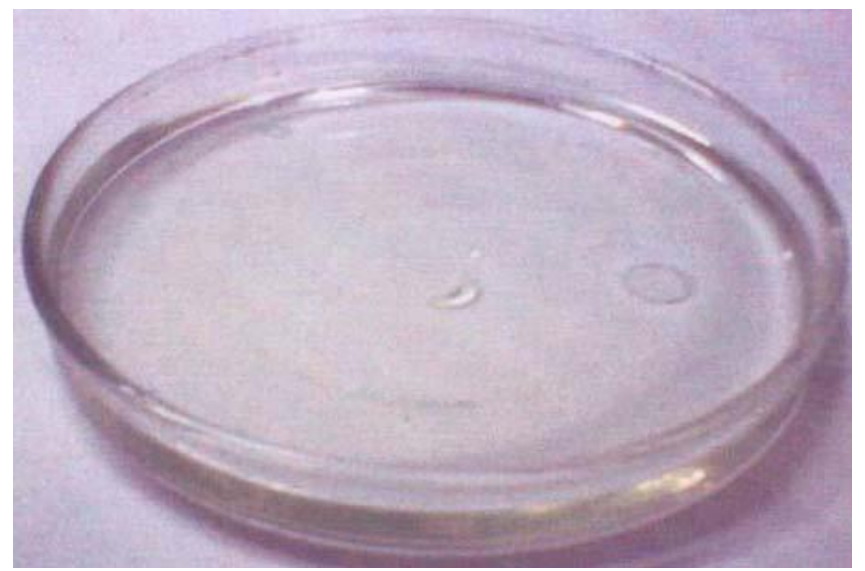

Fig.1 Phylogenetic tree showing the relationship among the nine isolates

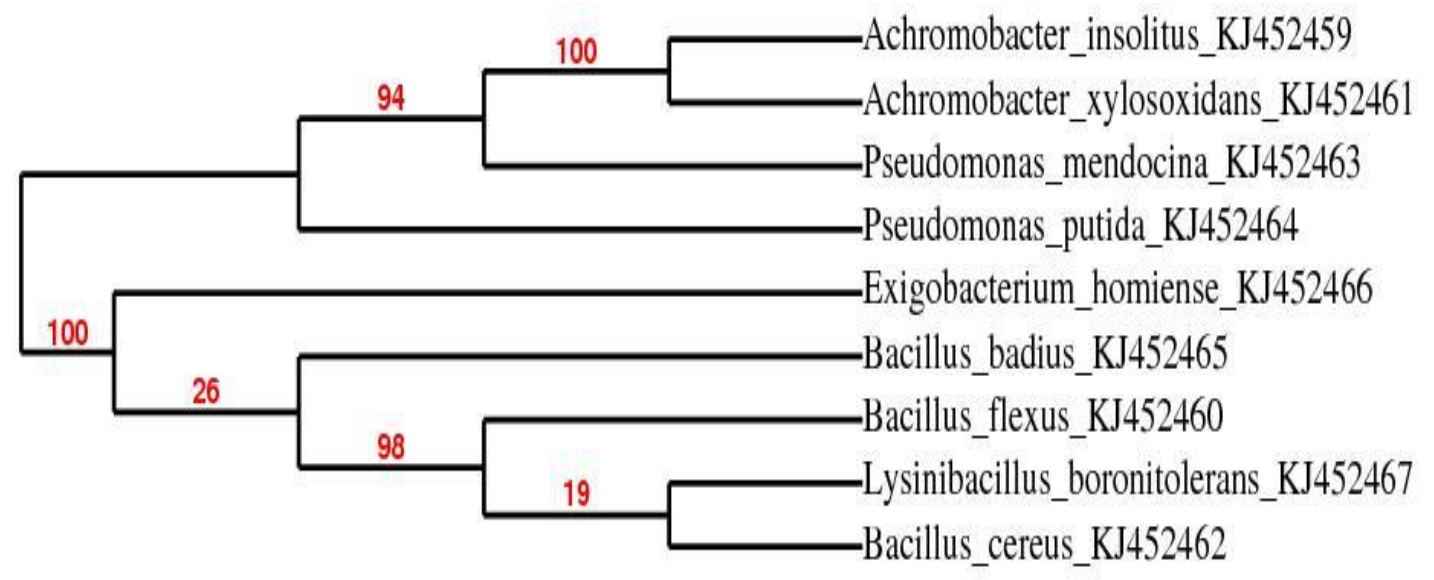


The isolates were further confirmed by $16 \mathrm{~s}$ rRNA sequencing. Based on DNA extracts of isolate, 16S rDNA which amplified by PCR using 35 cycles and primers $16 \mathrm{sF}$ and $16 \mathrm{sR}$ was got sequence result and listed in table 2 . The bacterial16s rDNA sequences were aligned with Blast search of NCBI databases. The sequence aligned have $99 \%$ similarity with Achromobacter denitrificans, Bacillus flexus, Achromobacter xylosoxidans, Bacillus cereus, Pseudomonas medocina, Pseudomonas putida, Bacillus badius, Lysinibacillus xylanilyticus, Exiguobacterium homiense, respectively. These results highlight the different group of bacterial genera involved in Biosurfactant production. Many scientists studied the biosurfactant production by various Pseudomonas species and by Bacillus species (Adriano et al., 1999). It is evident from the study that when environment was contaminated with petroleum and oil components the proportion of hydrocarbon degrading microorganisms increases rapidly. High numbers of certain hydrocarbon degrading microorganisms from an environment implies that those organisms are the active degraders of that environment. The presence of oil degrading organisms in the polluted soil is clear indication that the indigenous microbes were carrying out their metabolic activity. The activities of these microorganisms could be responsible for the bioremediation of the environment.

Table 3 indicated the nine strains were screened for biosurfatant production test like Haemolytic assay, Methylene blue agar plate, Emulsification index and production of Rhamnolipid. The nine strains are positive to Haemolytic assay, Methylene blue agar plate, Drop collapsing test. The emulsification index and production of Rhamnolipid was highest in Pseudomonas Putida.. Kiran et al., (2010) suggested that the single screening method is unsuitable for identifying all types of biosurfactants, and recommended that more than one screening method should be included during primary screening to identify potential biosurfactant producers. In the present study, nine bacterial species positive for biosurfactant production were isolated from river water sample by plate and dilution technique. They were further screened for biosurfactant activities by haemolytic assay, methylene blue agar plate, drop collapsing test, emulsification index, rhamnolipid as reported by satbute et al., 2008 that more than one screening method should be included in the primary screening as to identify potential biosurfactant producer (Table 3). The results on methylene blue agar media were similar to the work done by Mulligan et al., (1984) and Mulligan et al., (1989), who have isolated the biosurfactant over producer mutants with methylene blue agar media. The flat appearance in microtitre plate confirmed the positive result for drop collapse test as suggested by Jain et al., (1991). The result of this research work is in line with those of Tabatabaee et al., (2005) and Jaysree et al., (2011) who confirmed the isolation of biosurfactant producing microorganisms from oil polluted samples. Also that biosurfactant producing micro organisms can displace oil on water oil interface and show $\beta$ - haemolysis on blood agar.Our study reports the isolation and subsequent characterization of new biosurfactant-producing isolates from the river water sample.

As seen from the table, Pseudomonas putida was found to produce a higher amount of surfactant when compared to other isolates. While the amount of biosurfactant produced by Pseudomonas putida was $0.89 \mathrm{mg} / \mathrm{ml}$. Thus, it is clear that the isolated organisms under favourable conditions can produce biosurfactants which help in bioremediation.

Results of the bioremediation tests using the nine isolates for the heavy metal zinc is provided in table 4 . As evident from the table, 
it is clear that the nine isolates have the ability to reduce the amount of zinc. While the use of Pseudomonas putida recorded a decrease in the level of zinc ranging from 32 to $73.20 \%$, when compared to the control. Further, the isolates recorded enhanced bioremediation rates with an increase in the concentration of heavy metals. However, among the nine isolates, Pseudomonas putida appeared to be a better candidate as it recorded a higher efficiency rate when compared to other eight isolates.

The results of the bioremediation studies using the nine isolates in the bioremediation of iron is presented in table 5. Here also, the isolates Pseudomonas putida recorded a decrease in iron content. However, Pseudomonas putida, appeared to be a better candidate when compared to other organisms. Rhamnolipid was able to reduce metal toxicity to microbial consortia in contaminated soils (Sandrin et al., 2003). Maslin and Maier (2000) studied the effect of rhamnolipid produced by various Pseudomonas sp strains on the phenanthrene degradation by indigenous population in two soils co-contaminated with phenanthrene and cadmium. Hazara et al., (2010) noted that $50 \%$ and $30 \%$ removal of lead and cadmium with $1 \% \quad(\mathrm{~V} / \mathrm{V})$ rhamnolipid extract. The results indicated the activity of biosurfactants in the removal of heavy metals. The present study indicated the use of biosurfactants in the bioremediation of metal contaminated sediment from the Uyyokondan river.

In conclusion, the present study indicates that out of nine isolates, Pseudomonas putida was found to be more effective in removing more than $50 \%$ Zinc and iron from the medium. The biosurfactants rhamnolipid might play a great role in the removal of these toxic heavy metals. The use of such biosurfactants produced by the bacterial strain Psudomonas putida may be used for the bioremediation of the heavy metal contaminated area of Uyyokondan river. In future, through further research on structural characterization, gene regulation of biosurfactant and cost of production is needed.

\section{Acknowledgement}

This research work was funded by University Grant Commission-Minor research project (SERO, Hyderabad), No: MRP-5505/15. The corresponding authors thanks UGC (SERO) for their constant financial support and guidance rendered throughout the period of study.

\section{References}

Adriano, D.C., Bollag, J.M., Frankenberger, Jr. W.T. and Sims, R.C. 1999. Bioremediation of contaminated soil. Agronomy, No. 37, American Society of Agronomy.

Altschul, F.S., Cish, W., Miller, W., Myers, W.F. and Lipman, D.J. 1990. Basic Local Allignment Search Tool. J. Mol. Biol., 215: $403-410$.

Benson, H.J. 2004. Microbiological application: laboratory manual in general microbiology. USA, McGraw Hill Publication, pp 470-491.

Chandrasekaran, E.V., Bemiller, J.N. 1980. Constituent analyses of glycosaminoglycans. Methods Carbohydr. Chem. 8:89-96. Hazra, C., Kundu, D., Ghosh, P., Joshi.

Cooper, D.G. and Goldenberg, B.G. 1987. Surface active agents from two Bacillus species. Appl. Environ. Microbiol., 53: 224- 229.

Hazra, C., Kundu, D., Ghosh, P., Joshi, S, Dandi, N., Chaudhari, A. 2011. Screening and identification of Pseudomonas aeruginosa AB4 for improved production, characterization and application of a glycolipid biosurfactant using lowcost agro-based raw materials. J. Chem. Technol. Biotechnol,. 86: 185-198.

Jaysree, R.C., Basu, S., Singh, P.P., Ghosal, T., Patra, A.P., Keerthi, Y. and Rajendran N. 
2011. Isolation of biosurfactant producing bacteria from environmental samples. Pharmacologyonline., 3: 1427-1433.

Jain, D.K., Collins-Thompson, D.L. and Lee, H. 1991. A drop collapsing test for screening biosurfactant producing microorganisms. J. Microbiol. Meth., 13: 271-279.

Kiran, G.S., Thomas, T.A., Selvin, J., Sabarathnam, B., Lipton, A.P. 2010. Optimization and characterization of a new lipopeptide biosurfactant produced by marine Brevibacteriumaureum MSA13 in solid state culture. Bioresour. Technol., 101: 2389-2396.

Maslin, P.M., Maier, R.M. 2000. Rhamnolipid enhanced mineralization of phenanthrene in organic metal co-contaminated soils. Bioremed. J., 4: 295-308.

Mulligan, C.N., Chow, T.Y.K. and Gibbs, B.F. 1989. Enhanced biosurfactant production by a mutant Bacillus subtilis strain. Appl. Microbiol. Biotechnol., 31: 486-489. 14.

Mullingan, C.N., Cooper, D.G. and Neufeld, R.J. 1984. Selection of microbes producing biosurfactants in media without hydrocarbons. J. Ferment. Technolo., 62: 311-314.

Nasr, S., Soudi, M.R., Mehrnia, M.R., Sarrafzadeh, M.H. 2009. Characterization of novel biosurfactant producing strains of Bacillus spp. isolated from petroleum contaminated soil. Iran. J. Microbiol., 2(1): 54-61.

Saitou, N. and Nei, M. 1987. The neighborjoining method: A new method for reconstructing phylogenetic trees. Mol. Biol. Evol., 4: 406-425

Sandrin, T.R., Chech, A.M., Maier, R.M. 2000. A rhamnolipid biosurfactant reduces cadmiumtoxicity during naphthalene biodegradation. Appl. Environ. Microbiol., 66: 4585-4588.

Satpute, S.K., Bhawsar, B.D., Dhakephalkar, P.K. and Chopade, B.A. 2008. Assessment of different screening methods for selecting biosurfactant producing marine bacteria. Ind. J. Mar. Sci., 37: 243-250.

Shinger, V., Pawlowski, J., and Marklund, V. 1992. Nucleotide sequence analysis and function functional analysis of the complete phenol/3, 4 dimethyl phenol catabolic pathway of pseudomoans sp strain. J. Bacteriol., 174: 711-724.

Syldatk, C., Wagner, F. 1987. Production of biosurfactants. In: Biosufactants and Biotechnology (Kosaric N, CairnsWL, Gray NCC, eds. New York: Marcel Dekker, 89-120.

Sinha, S.N. 2006. Focus on College Practical Microbiology. Rita Book Agency. Kolkata, pp 331.

Syldatk, C., Wagner, F. 1987. Production of biosurfactants. In: Biosufactants and Biotechnology (Kosaric N, CairnsWL, Gray NCC, eds. New York: Marcel Dekker, 89-120.

Tabatabaee, A., Assadi, M.M., Noohi, A.A \&Sajadian, V.A. 2005. Isolation of biosurfactant producing bacteria from oil reservoirs. Iranian J. Env. Health. Sci Eng, 2(1): 6-12.

Youssef, N.H., Duncan, K.E., Nagle, D.P., Savage, K.N., Knapp, R.M. and McInerney, M.J. 2004.Comparision of methods to detect biosurfactant production by diverse microorganism. $J$. Microbiol. Mech., 56: 339 -347.

Zajic, J.E., Panchel, C.J. 1976. Bio-emulsifiers. CRC Crit. Rev. Microbiol., 5: 39-66.

\section{How to cite this article:}

Meenakshisundaram, M. and Pramila, M. 2017. Detoxification of Heavy Metals Using Microbial Biosurfactant. Int.J.Curr.Microbiol.App.Sci. 6(3): 402-411. doi: https://doi.org/10.20546/ijcmas.2017.603.046 